\title{
Deep neuromuscular blockade versus remifentanyl or sevoflurane to augment measurable laparoscopic workspace during bariatric surgery
}

Mulier J., Dillemans B. ${ }^{\mathrm{b}}$

a. AZ Sint Jan Brugge-Oostende, Dept of Anaesthesiology \& Intensive Care, Bruges, Belgium, b. AZ Sint Jan Brugge-Oostende, Dept of Surgery, Bruges, Belgium

\section{Background:}

It is unclear whether anesthetics, deep neuromuscular blockade (NMB), or high-dose opioids increase laparoscopic workspace. We were able to objectively gauge the laparoscopic workspace, using abdominal compliance (C) and pressure at zero volume (PV0) calculated from a 3-point measurement of the abdominal pressurevolume relationship.(1)

\section{Methods:}

This study was approved by our institutional ethics committee. Upon granting written informed consent, a total of 50 patients $>18$ years old who elected laparoscopic gastric bypass surgery were enrolled. Anesthesia was induced by administering propofol $(3 \mathrm{mg} /$ $\mathrm{kg}$ IBW $)$, ketamine $(0.25 \mathrm{mg} / \mathrm{kg}$ IBW $)$, dexmedetomidine $(1 \mathrm{ug} / \mathrm{kg}$ IBW as 15 -min loading dose), lidocaine (1.5 mg/kg IBW), and succinylcholine $(1 \mathrm{mg} / \mathrm{kg}$ total body weight). For maintenance anesthesia, propofol $(5-10 \mathrm{mg} / \mathrm{kg} \mathrm{IBW} / \mathrm{h})$, lidocaine $(0.75-2.25 \mathrm{mg} /$ $\mathrm{kg} \mathrm{IBW} / \mathrm{h})$, dexmedetomidine $(0.5-1.4 \mathrm{ug} / \mathrm{kg} \mathrm{IBW} / \mathrm{h})$, and ketamine $(0.125-0.375 \mathrm{mg} / \mathrm{kg} \mathrm{IBW} / \mathrm{h})$ were infused and all adapted according to BIS value (kept around 40) and hemodynamic parameters (HR kept below 100 and SAP below $140 \mathrm{mmHg}$ ).

After insufflating the abdomen, the first trocar was placed and its position verified, and the stomach was visually confirmed as emptied (by gastric tube). The first APVR measurement was taken by the surgeon as follows: All air was expelled from the abdomen by manual pressure and rotation of the open trocar. The abdomen was then re-inflated incrementally to $0.5,1.0$, and 1.5 liters of intra-abdominal volume (IAV); and at each point, the intraabdominal pressure (IAP) was measured, with inflation stopped for a short moment. The lowest IAP during an insufflation stop is the end expiration pressure. (maximum, $15 \mathrm{~mm} \mathrm{Hg}$ ). The abdominal end expiration pressure-volume data were fit using a linear least squares regression, where the slope is abdominal elastance (E), the intercept is the abdominal pressure at zero volume (PV0), and the predicted inflated volume at $15 \mathrm{mmHg}$ is $(15-\mathrm{PV} 0) / \mathrm{E}$. (Mulier 2009)

Following APVR determination, patients in group A received a bolus of remifentanil ( $2 \mu \mathrm{g} / \mathrm{kg}$ IBW), followed by remifentanyl infusion (10-50 ug/kg IBW/h). Propofol and dexmedetomidine were also infused, but dosages were adjusted after further APVR determinations.

Members of Group B each received sevoflurane inhalation in $\mathrm{N}_{2} /$ $\mathrm{O}_{2}$ via fresh gas flush of the ventilator (using end-tidal control function) until end-tidal concentration reached $1 \mathrm{MAC}$, and the propofol infusion was stopped.

A bolus dose of rocuronium ( $1 \mathrm{mg} / \mathrm{kg}$ IBW) was given to each member of Group $\mathrm{C}$, while propofol and dexmedetomidine infusion was continued.

After 5 min, APVR was measured again by the same method.

After the second APVR measurement the insufflator was set at 15 $\mathrm{mmHg}$, the IAV was calculated and the surgeon continued the laparoscopy. He was polled to determine if more working space was needed for full operative access and if muscle movements took place and disturbed his work. The objective measured IAV above which never a complaint of insufficient workspace was given is determined as the minimum required IAV. The objective measured IAV below which there is always a complaint of insufficient workspace is determined as the IAV that should always be avoided.

Results: Minimum workspace required at $15 \mathrm{mmHg}$ :

- Insufficient workspace when IAV: 0 - 3.11 liters $(2.07 \pm 1.01)$,

- Sufficient workspace when IAV: 2.58 - 8.5 liters $(4.58 \pm 1.21)$.

- The minimum IAV $=3.11$ liters and always avoid $<2.58$ liters
Results and Discussion:

Table 1: Demographics of the three treatment groups

\begin{tabular}{|llllll|}
\hline Mean +/- SD & A/Remifentanyl B/Sevoflurane & C/Rocuronium & D/excluded & $\mathrm{p}$ value \\
Age & $40.67(7.33)$ & $36.50(8.40)$ & $38.93(5.54)$ & $40,13(11.94)$ & $\mathrm{p}>0,05$ \\
Man/woman & $4 / 9$ & $4 / 10$ & $4 / 11$ & $2 / 6$ & $\mathrm{p}>0,05$ \\
Gravidity & $1.63(0.98)$ & $1.44(1.07)$ & $1.00(0.83)$ & $0.67(0.93)$ & $\mathrm{p}>0,05$ \\
Length & $168(8)$ & $171(12)$ & $170(9.0)$ & $167.88(10.23)$ & $\mathrm{p}>0,05$ \\
Weight & $111(19)$ & $116(19)$ & $116(33)$ & $118.63(11.65)$ & $\mathrm{p}>0,05$ \\
Weight drop & $\mathbf{6 . 0 ( 8 . 3 2 )}$ & $\mathbf{3 . 4 3 ( 3 . 7 5 )}$ & $\mathbf{5 . 9 8 ( 6 . 1 7 )}$ & $\mathbf{1 . 6 3 ( 2 . 5 0 ) *}$ & $\mathbf{0 , 0 1 4}$ \\
BMI & $39.14(5,13)$ & $39.19(2.74)$ & $39.88(7.10)$ & $42.22(4.32)$ & $\mathrm{p}>0,05$ \\
*Kolmogorov-Smirnov & & & & \\
\hline
\end{tabular}

Table 2: Muscle movements after receiving the test drugs. Insufficient workspace following the second APVR, with IAP at $15 \mathrm{mmHg}$.

\begin{tabular}{|llll|}
\hline Group & lap possible & insufficient space & movements \\
Failure to insufflate (8) & 0 & not measurable & 8 \\
A: Remifentanyl (12) & $8(66 \%)$ & 4 (roc given) & $\mathbf{0}$ \\
B: Sevoflurane (14) & $\mathbf{0 ( 0 \% )}$ & 6 (roc given) & 8 (roc given) \\
C: Rocuronium (16) & $13(81 \%)$ & 3 (IAP increase) & $\mathbf{0}$ \\
\hline
\end{tabular}

Table 3: Who had movements, who had appreciably insufficient workspace at an insufflation pressure of $15 \mathrm{mmHg}$ ?

\begin{tabular}{|llll|}
\hline Mean (SD) & movements & $\begin{array}{l}\text { insufficient } \\
\text { workspace }\end{array}$ & $\begin{array}{l}\text { suf space / } \\
\text { no movements }\end{array}$ \\
Age & $44(14)$ & $53(18) *$ & $65(19)$ \\
Man/woman & $3 / 5$ & $2 / 10$ & $6 / 15$ \\
Length & $172.75(12.59)$ & $168.33(8.37)$ & $169.38(9.23)$ \\
Weight & $118.31(22.58)$ & $117.46(13.69)$ & $118.83(30.87)$ \\
Weight loss & $6.36(7.2)$ & $7.07(8.1)$ & $3.32(3.7)$ \\
BMI & $39.37(3.61)$ & $38.87(2.88)$ & $39.76(6.74)$ \\
Elastance & $2.00(0.53)$ & $3.77(1.36)^{*}$ & $2.07(0.55)$ \\
PV0 & $6.71(0.84)$ & $8.21(3.93)^{*}$ & $5.99(1.15)$ \\
Workspace & $4.45(1.45)$ & $2.07(1.01)^{*}$ & $4.58(1.21)$ \\
\hline
\end{tabular}

Table 4: Calculated E and PV0, Insufflation volumes achieved at 15 $\mathrm{mmHg}$ before and after treatment.

\begin{tabular}{|c|c|c|c|c|c|c|}
\hline $\begin{array}{l}\text { Group mean (SD) } \\
{ }^{\circ} \mathrm{p}\end{array}$ & $\begin{array}{l}\mathrm{E} \\
0.453\end{array}$ & ${ }^{*} \mathrm{p}$ & $\begin{array}{l}\text { PV0 } \\
0.001\end{array}$ & ${ }^{*} \mathrm{p}$ & $\begin{array}{l}\text { IAV at } 15 \mathrm{mmH} \\
0.007\end{array}$ & \\
\hline A: before & $2,58(1,0)$ & & $6,50(1,5)$ & & $3,64(1,21)$ & \\
\hline After Remifentanyl & $12,50(0,8)$ & 0.86 & $6,58(1,39)$ & 0.59 & $3,65(1,14)$ & 0.78 \\
\hline B: before & $2,57(0,76)$ & & $7,90(3,37)$ & & $3,11(1,70)$ & \\
\hline After Sevoflurane & $2,71(1,44)$ & 0.91 & $8,29(3,60)$ & 0.63 & $3,22(2,12)$ & 0.98 \\
\hline C: before & $2,66(1,38)$ & & $7,30(1,16)$ & & $3,35(1,13)$ & \\
\hline After Rocuronium & $2,53(1,23)$ & 0.59 & $5,70(1,00)$ & 0.001 & $4,29(1,64)$ & 0.086 \\
\hline
\end{tabular}

Required IPA to achieve 31 IAV

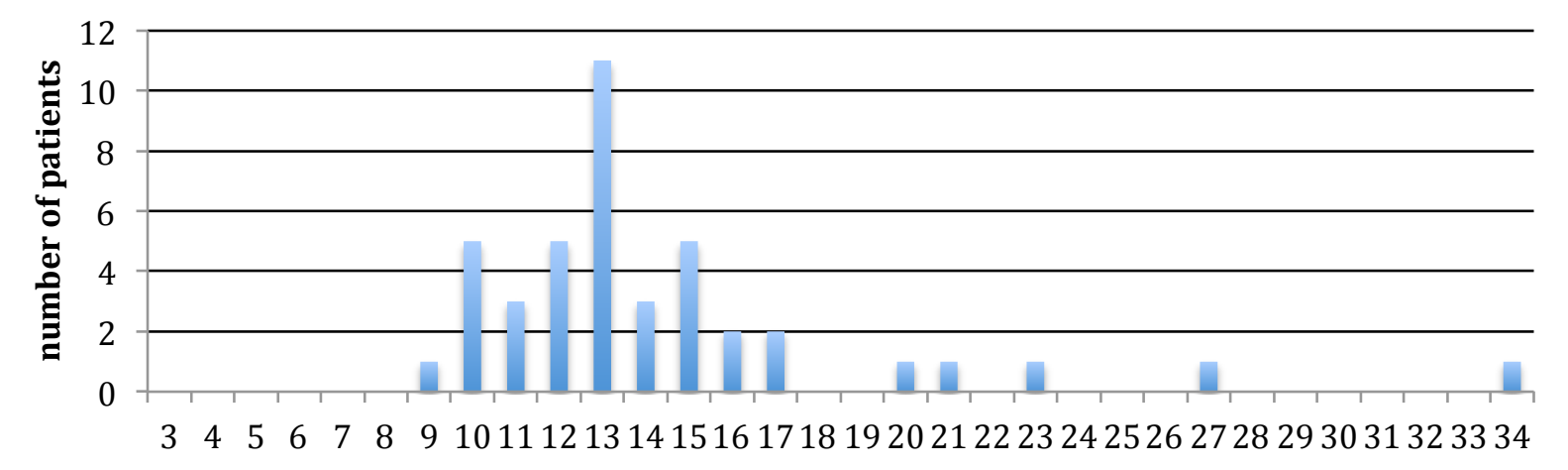
required IAP $\mathrm{mmHg}$

\section{Conclusions:}

- The use of remifentanyl and NMB prevented muscle movements, but only deep NMB reduced PV0 and increased laparoscopic workspace.

- Pre operative weight drop facilitated insufflation without NMB.

- Calculation of E and PV0 helped implement the lowest IAP possible without compromise of laparoscopic workspace.

- At our center, a 3-liter insufflation volume seems minimal for optimal bariatric surgery, although this was unattainable in all the patients studied (despite some exclusions) if restricting insufflation pressure to a maximum of $15 \mathrm{mmHg}$.

\section{References:}

1. Mulier $\mathrm{J}$ et al. On the abdominal pressure volume relationship. The Internet Journal of Anesthesiology. 2009;21:1.

2. Dillemans B et al. Standardization of the Laparoscopic Roux-en Y Gastric Bypass for Obesity Reduces Early Immediate Postoperative Morbidity and Mortality. Obes Surg 2009;19:1355-64.

3. Kopman A et al. Laparoscopic Surgery and Muscle Relaxants: Is Deep Block Helpful? Anesth Analg 2015;120:51-8. 